\title{
WPS3428
}

\section{Who Suffers from Indoor Air Pollution? Evidence from Bangladesh}

\author{
Susmita Dasgupta* \\ Mainul Huq \\ M. Khaliquzzaman \\ Kiran Pandey \\ David Wheeler \\ Development Research Group \\ World Bank
}

World Bank Policy Research Working Paper 3428, October 2004

The Policy Research Working Paper Series disseminates the findings of work in progress to encourage the exchange of ideas about development issues. An objective of the series is to get the findings out quickly, even if the presentations are less than fully polished. The papers carry the names of the authors and should be cited accordingly. The findings, interpretations, and conclusions expressed in this paper are entirely those of the authors. They do not necessarily represent the view of the World Bank, its Executive Directors, or the countries they represent. Policy Research Working Papers are available online at http://econ.worldbank.org.

* Authors' names in alphabetical order. We would like to express our appreciation to the field survey team of the Development Policy Group, for their excellent air-quality monitoring work under difficult conditions. We are also grateful to Kseniya Lvovsky, Maureen Cropper, Douglas Barnes, Bart Ostro and Paul Martin for useful comments and suggestions. Financial support for this study has been provided by Trust Funds through the Knowledge for Change Program of the World Bank's Development Economics Vice-Presidency, and by the Development Research Group. 


\begin{abstract}
In this paper, we investigate individuals' exposure to indoor air pollution (IAP). Using new survey data from Bangladesh, we analyze exposure at two levels: differences within households attributable to family roles, and differences across households attributable to income and education. Within households, we relate individuals' exposure to pollution in different locations during their daily round of activity. We find high levels of exposure for children and adolescents of both sexes, with particularly serious exposure for children under 5. Among prime-age adults, we find that men have half the exposure of women (whose exposure is similar to that of children and adolescents). We also find that elderly men have significantly lower exposure than elderly women. Across households, we draw on results from our previous paper (Dasgupta, et al., 2004), which relate pollution variation across households to choices of cooking fuel, cooking locations, construction materials and ventilation practices. We find that these choices are significantly affected by family income and adult education levels (particularly for women). Overall, we find that the poorest, least-educated households have twice the pollution levels of relatively high-income households with highly-educated adults.
\end{abstract}

Overall, we find that young children and poorly-educated women in poor households face pollution exposures that are four times those for men in higher-income households organized by more highlyeducated women. In our previous paper, we recommended feasible changes in cooking locations, construction materials and ventilation practices that could greatly reduce average household pollution levels. In this paper, we consider measures for narrowing the exposure gap among individuals within households. We focus particularly on changes for infants and young children, since they suffer the worst mortality and morbidity from indoor air pollution, but our findings also apply to women and adolescents. Our recommendations for reducing their exposure are based on a few simple, robust findings: Hourly pollution levels in cooking and living areas are quite similar because cooking smoke diffuses rapidly and nearly-completely into living areas. However, outdoor pollution is far lower. At present, young children are only outside for an average of 3 hours per day. For children in a typical household, pollution exposure can be halved by adopting two simple measures: increasing their outdoor time from 3 to 5 or 6 hours per day, and concentrating outdoor time during peak cooking periods. We recognize that weather and other factors may intervene occasionally, and that child supervision outdoors may be difficult for some households. However, the potential benefits are so great that neighbors might well agree to pool outdoor supervision once they became aware of the implications for their children's health. 


\section{Introduction}

Indoor air pollution from burning wood, animal dung and other biofuels is a major cause of acute respiratory infections (ARI), which constitute the most important cause of death for young children in developing countries (Murray and Lopez, 1996). Acute lower respiratory infection (ALRI), the most serious type of ARI, is often associated with pneumonia (Kirkwood et al., 1995). ALRI accounts for $20 \%$ of the estimated 12 million annual deaths of children under five, and about $10 \%$ of perinatal deaths (WHO, 2001; Bruce, 1999). Nearly all of these deaths occur in developing countries, with the heaviest losses in Asia (42\% of total deaths) and Africa (28\%) (Murray and Lopez, 1996). Through its effect on respiratory infections, indoor air pollution (IAP) is estimated to cause between 1.6 and 2 million deaths per year in developing countries (Smith, 2000). Most of the dead are in poor households and approximately 1 million are children (Smith, 1993; Smith, et al., 1993; Smith and Mehta, 2000). Table 1 provides estimates of health damage from IAP by region.

Table 1: Annual Disease Burden From Indoor Air Pollution (Early 1990’s)

\begin{tabular}{|l|r|r|r|}
\hline \multicolumn{1}{|c|}{ Region } & $\begin{array}{l}\text { Deaths } \\
\text { ('000) }\end{array}$ & $\begin{array}{c}\text { Illness } \\
\text { Incidence } \\
\text { ('000,000) }\end{array}$ & $\begin{array}{c}\text { DALYs } \\
\text { ('000,000) }\end{array}$ \\
\hline China & 516.5 & 209.7 & 9.3 \\
\hline India & 496.1 & 448.4 & 16.0 \\
\hline Sub-Saharan Africa & 429.0 & 350.7 & 14.3 \\
\hline Other Asia \& Pacific Islands & 210.7 & 306.4 & 6.6 \\
\hline Mid-East and North Africa & 165.8 & 64.2 & 5.6 \\
\hline Latin America \& Caribbean & 29.0 & 58.2 & 0.9 \\
\hline Total & $1,800.0$ & $1,400.0$ & 53.0 \\
\hline
\end{tabular}

Source: World Bank (2002), drawing on Smith and Mehta (2000) and Von Schrinding, et al., (2001)

The size of IAP's estimated impact has prompted the World Bank (2001) and other international development institutions to identify reduction of indoor air pollution as a critical objective for the coming decade. The current scientific consensus is that most respiratory health damage comes from

\footnotetext{
1 DALYs, or disability-adjusted life years, combine life-years lost from premature death and fractional years of healthy life lost from illness and disability (Murray and Lopez 1996).
} 
inhalation of respirable particles whose diameter is less than 10 microns (PM10), and recent attention has focused particularly on fine particles (PM2.5).

In a previous paper, we analyzed variations in average IAP levels across Bangladeshi households (Dasgupta, et al., 2004). We found that common variations in fuel use, cooking locations, construction materials and ventilation characteristics lead to large differences in IAP. Non-fuel characteristics are so influential that some households using "dirty" biomass fuels have $\mathrm{PM}_{10}$ concentrations comparable to those in households using clean fuels such as liquid natural gas. Under adverse conditions, on the other hand, Bangladeshi households using dirty fuels can experience 24-hour average $\mathrm{PM}_{10}$ concentrations as high as $800 \mathrm{ug} / \mathrm{m}^{3}$.

Such concentrations are far higher than outdoor $\mathrm{PM}_{10}$ levels considered dangerous for public health in industrial societies (Galassi et al., 2000). In those societies, however, use of clean fuels is so pervasive that attention focuses on outdoor pollution. In biofuel-using Bangladeshi households, particularly in rural areas, the calculus is often reversed: Indoor air pollution (IAP) may be much worse than outdoor pollution, and health risks may be severe for household members who are exposed to IAP for long periods during the day.

In this paper, we use our survey data to estimate the incidence of IAP exposure for family members by age-sex group, with a particular focus on young children. We investigate the two major sources of differential exposure: individuals' time spent in different locations (cooking areas, living areas and outside), and hourly fluctuations in pollution from cooking. We also assess the effect of parents' income and education on average household pollution levels.

The remainder of the paper is organized as follows. In Sections 2-5 we study the sources of variation in individuals' exposure to pollution within households. The four sections analyze individuals' daily location patterns, their interaction with daily cycles in pollution from cooking, the 
implications for pollution exposure, and some possible remedies for the most vulnerable family members (particularly young children). Section 6 compares our results with those in a recent study for India. In Section 7, we assess the effects of income and adult education on both determinants of exposure: average pollution levels across households, and patterns of activity within households. Section 8 provides a summary and conclusions.

\section{Daily Location Patterns in Bangladeshi Households}

Within households, individuals' pollution exposure may vary significantly because they spend very different amounts of time in cooking areas, living areas, and outside the house. Table 2 reports average daily hours in the three locations for a representative sample of 4,612 individuals drawn from 600 households in rural, peri-urban and urban areas of seven Bangladeshi regions (Figure 1): Rangpur (491 individuals) in the Northwest, Sylhet (578) in the Northeast, Rajshahi (491) and Jessore (490) in the West, Faridpur (497) and Dhaka $(1,493)$ in the Center, and Cox's Bazar (572) in the Southeast.

Table 2 present statistics by sex, because gender roles are quite different in Bangladeshi households. Among age groups, we distinguish infants (age 0-1) and young children (age 1-5) because they are most vulnerable to air pollution, and most tied to their mothers' patterns of activity. We divide school-age youths into two groups with different patterns of school attendance that may have implications for exposure to indoor pollution: students 6-8 years of age, who attend school in the morning (9:00 a.m. - 12:00 a.m.), and students 9-19 years of age who attend from midday until late afternoon (11:30 a.m. $-4: 30$ p.m.). We divide adults into prime-age (20-60) and older (60+) categories.

Table 2 shows that time-location patterns are very similar for infants of both sexes. They spend relatively short periods in cooking areas ( 1 hour per day), very long periods in living areas (20 hours/day), and the residual time ( 3 hours) outside the house. Infants spend more time indoors than 
any other age group. Children from 1-5 exhibit a very similar pattern, with little difference between the sexes. After age 5, however, gender differences emerge strongly. In cooking areas, the gap between female and male hours rises steadily through maturity (to 3.6 extra hours for women 20-60), and then falls substantially for older women. Living areas exhibit a similar pattern, with the gap between women and men increasing steadily from early adolescence through old age. Men spend much more time outside of the house than women: The gap is 3.4 hours for adolescents, 6.5 hours for adults $20-60$, and 4.5 hours for older adults.

Table 2: Mean Daily Hours by Location: Seven Regions in Bangladesh

\begin{tabular}{|r|c|c|c|c|c|c|r|r|r}
\hline & \multicolumn{3}{|c|}{ Female } & \multicolumn{3}{c|}{ Male } & \multicolumn{3}{c}{ Male - Female } \\
\hline Age & $\begin{array}{c}\text { Cooking } \\
\text { Area }\end{array}$ & $\begin{array}{c}\text { Living } \\
\text { Areas }\end{array}$ & Outside & $\begin{array}{c}\text { Cooking } \\
\text { Area }\end{array}$ & $\begin{array}{c}\text { Living } \\
\text { Areas }\end{array}$ & Outside & $\begin{array}{c}\text { Cooking } \\
\text { Area }\end{array}$ & $\begin{array}{c}\text { Living } \\
\text { Areas }\end{array}$ & Outside \\
\hline & & & & & & & & & \\
\hline $0-1$ & 1.12 & 20.04 & 3.01 & 1.11 & 19.29 & 3.57 & -0.01 & -0.75 & 0.56 \\
\hline $2-5$ & 1.08 & 18.44 & 4.52 & 0.93 & 18.13 & 4.97 & -0.15 & -0.31 & 0.45 \\
\hline $6-8$ & 1.01 & 16.40 & 6.61 & 0.48 & 16.41 & 7.17 & -0.52 & 0.01 & 0.56 \\
\hline $9-12$ & 1.32 & 15.55 & 7.19 & 0.31 & 15.61 & 8.06 & -1.01 & 0.06 & 0.87 \\
\hline $13-19$ & 2.38 & 15.71 & 5.97 & 0.28 & 14.33 & 9.41 & -2.10 & -1.38 & 3.44 \\
\hline $20-60$ & 3.75 & 16.05 & 4.27 & 0.19 & 13.07 & 10.79 & -3.56 & -2.98 & 6.52 \\
\hline $60+$ & 1.48 & 19.76 & 2.93 & 0.17 & 16.56 & 7.37 & -1.31 & -3.20 & 4.45 \\
\hline
\end{tabular}

\section{Daily Pollution Cycles}

To assess the implications of Table 2 for pollution exposure, we need information on the levels and daily variations of $\mathrm{PM}_{10}$ pollution in cooking areas, living areas, and the outside the house. A previous paper by the authors (Dasgupta, et al., 2004) has documented extensive indoor air-quality monitoring in the peri-urban area of Narshingdi (Dhaka region). ${ }^{2}$ In 236 Narshingdi households, the average daily $\mathrm{PM}_{10}$ concentration is $260 \mathrm{ug} / \mathrm{m}^{3}$ for cooking areas and $210 \mathrm{ug} / \mathrm{m}^{3}$ for living areas. To estimate outdoor concentrations in peri-urban and rural areas, we have taken ambient readings in

\footnotetext{
2 Although this region is near Dhaka, many of the sampled households are in rural settings.
} 
Figure 1: Survey Areas in Bangladesh

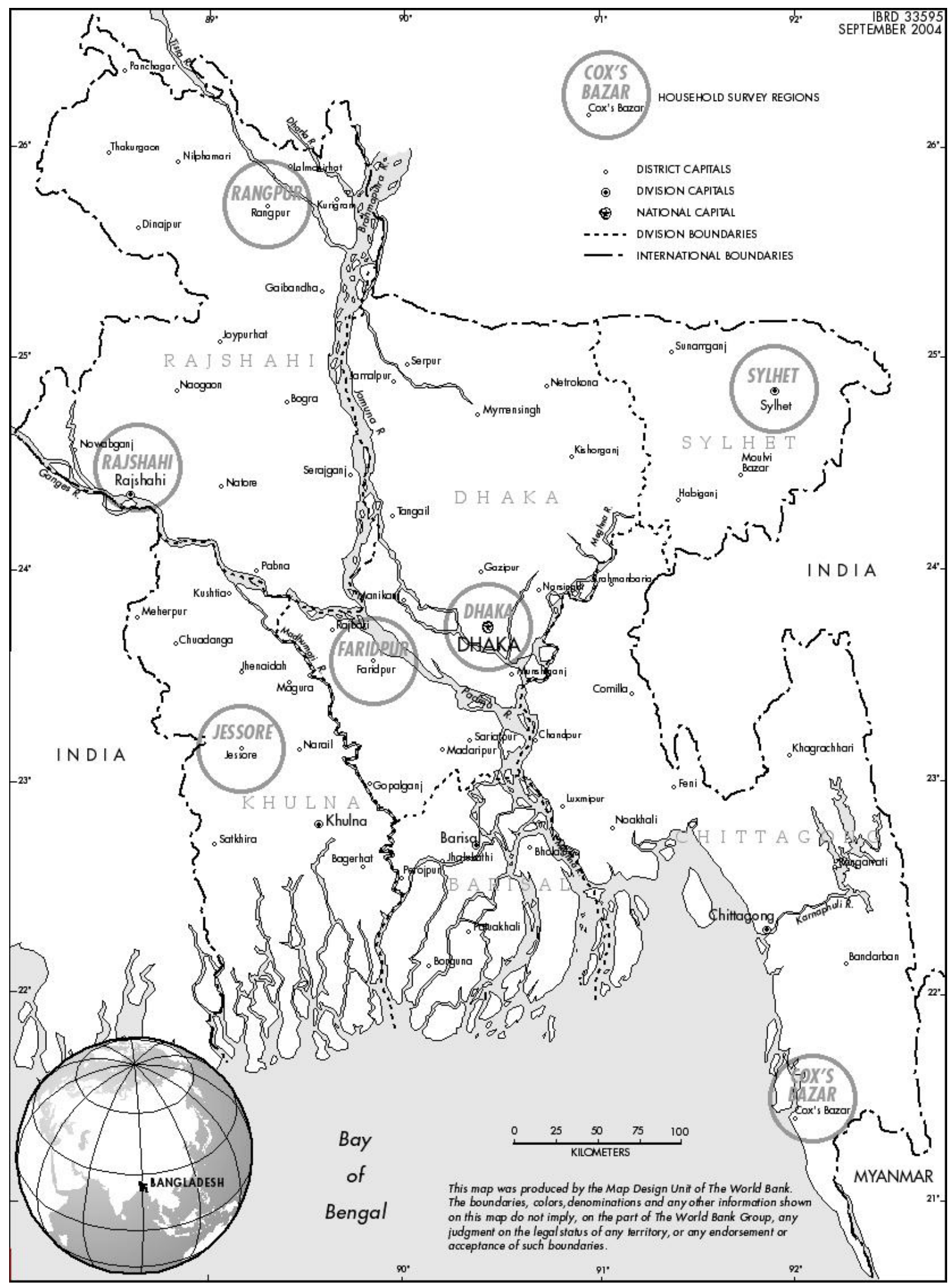


Narshingdi (8 monitoring points), and rural areas of Jessore (16 points) and Rangpur (11 points). Average outdoor concentrations in the three locations are 36,48 , and $62 \mathrm{ug} / \mathrm{m}^{3}$, respectively. The overall average for 35 monitoring points is $50 \mathrm{ug} / \mathrm{m}^{3}$, which we have adopted as our estimate of outdoor pollution for this exercise.

In the previous paper, we have shown that pollution generated in cooking areas diffuses almost immediately into living areas. ${ }^{3}$ As a result, pollution in both areas exhibits strong pollution cycles in response to fuel combustion for cooking. Drawing on information from continuous, 24-hour monitoring of $\mathrm{PM}_{10}$ in 27 households in Narshingdi, Figure 2 displays a typical daily pollution cycle as a 24-hour plot of the ratio of the hourly mean $\mathrm{PM}_{10}$ concentration to the daily mean concentration. ${ }^{4}$ Its distinguishing features include two peaks during morning and evening cooking times, when pollution rises to over 3 times the daily average, and extensive periods in the afternoon and evening when pollution is substantially lower than the daily average. Daily indoor pollution cycles are also reflected in outdoor ambient cycles, as many houses emit cooking smoke. Figure 3 illustrates a typical ambient cycle, drawn from 24-hour monitoring at 7 points in rural villages of Jessore and Rangpur. ${ }^{5}$ We combine mean indoor and outdoor pollution concentrations with the hourly ratios in Figures 2 and 3 to produce Table 3 , which provides hourly estimates of $\mathrm{PM}_{10}$ in cooking areas, living areas and outside the house.

3 For illustrations of the close relationship, see Dasgupta, et al. (2004), Figure 2, p. 12.

4 Of course, households differ significantly in the timing of daily peaks; some have three rather than two, and there are also significant differences in peak levels and change gradients. Figure 2 represents the central tendency in the observed patterns for 27 households..

This cycle is clearly different from the cycle in Figure 2, for two apparent reasons. First, the outdoor cycle reflects the combined effect of fuel-burning in many households, whose daily cycles reach peaks at different times, and at different $\mathrm{PM}_{10}$ emissions intensities. However, this does not explain the large difference in the relative size of the two outdoor peaks, as compared with rough parity for the indoor peaks. Since the outdoor pattern is reproduced across several widelyseparated monitoring points, we hypothesize that different atmospheric conditions lead to more pronounced accumulation and duration of suspended particulates in the evening. Alternatively, preparation of evening meals may cluster more tightly in time, leading to more concentrated loading of $\mathrm{PM}_{10}$ in the evening. Future research may shed more light on this phenomenon. 
Figure 2: Daily $\mathbf{P M}_{10}$ Pattern for Cooking and Living Areas

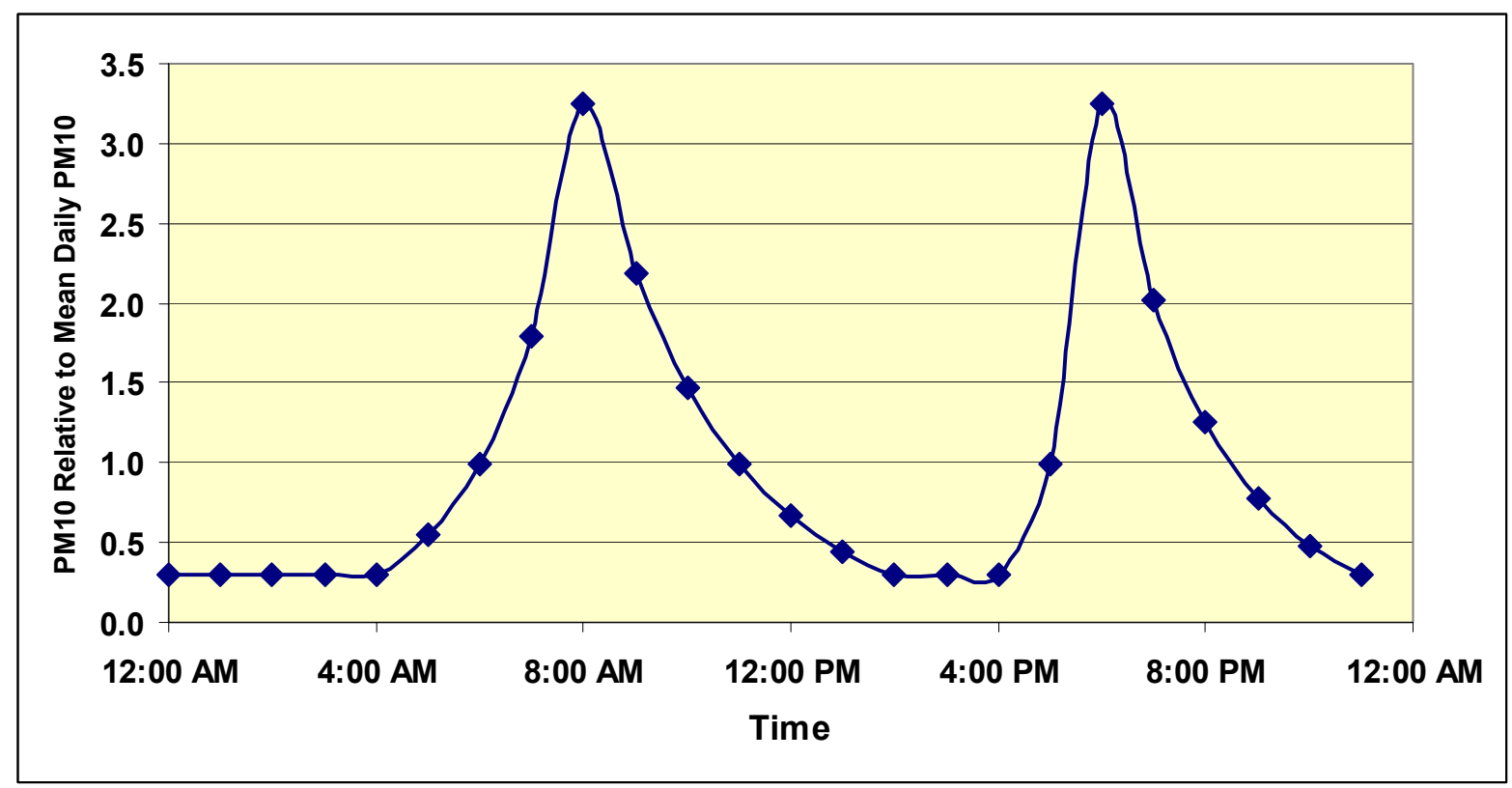

Figure 3: Daily Ambient (Outdoor) Pollution Pattern in Rural Villages

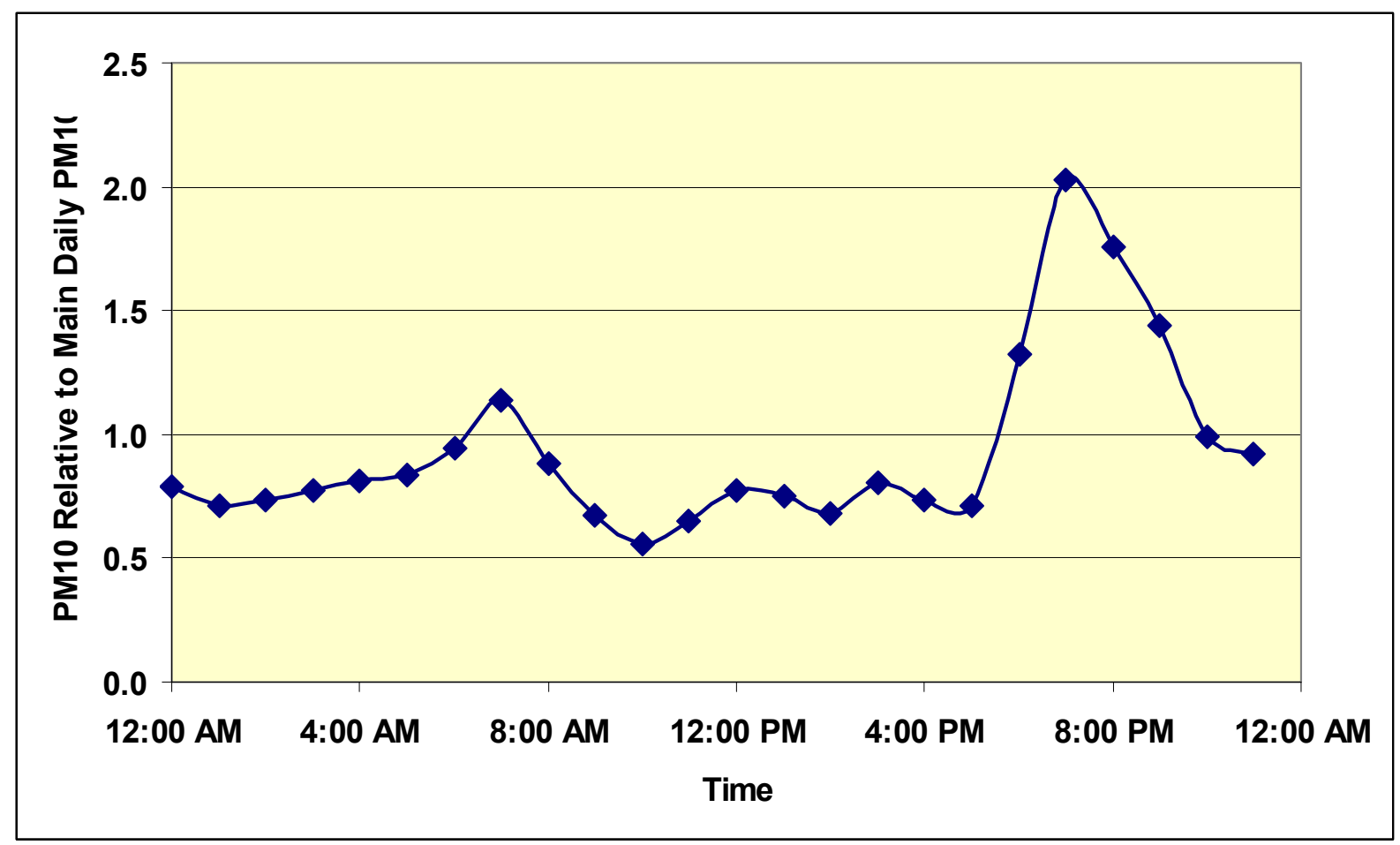


Table 3: Daily $\mathbf{P M}_{10}$ Concentrations, by Location

\begin{tabular}{|c|c|c|c|}
\hline Time & Kitchen & $\begin{array}{l}\text { Living } \\
\text { Area }\end{array}$ & Ambient \\
\hline 12:00 AM & 78 & 63 & 40 \\
\hline 1:00 AM & 78 & 63 & 35 \\
\hline $2: 00 \mathrm{AM}$ & 78 & 63 & 37 \\
\hline $3: 00$ AM & 78 & 63 & 39 \\
\hline 4:00 AM & 78 & 63 & 41 \\
\hline 5:00 AM & 142 & 114 & 42 \\
\hline 6:00 AM & 257 & 207 & 47 \\
\hline $7: 00$ AM & 466 & 376 & 57 \\
\hline 8:00 AM & 845 & 683 & 44 \\
\hline 9:00 AM & 568 & 459 & 33 \\
\hline 10:00 AM & 382 & 308 & 28 \\
\hline $11: 00 \mathrm{AM}$ & 257 & 207 & 33 \\
\hline 12:00 PM & 173 & 139 & 39 \\
\hline 1:00 PM & 116 & 94 & 37 \\
\hline 2:00 PM & 78 & 63 & 34 \\
\hline 3:00 PM & 78 & 63 & 40 \\
\hline 4:00 PM & 78 & 63 & 37 \\
\hline 5:00 PM & 257 & 207 & 36 \\
\hline 6:00 PM & 845 & 683 & 66 \\
\hline 7:00 PM & 525 & 424 & 101 \\
\hline 8:00 PM & 326 & 263 & 88 \\
\hline 9:00 PM & 202 & 163 & 72 \\
\hline 10:00 PM & 126 & 101 & 50 \\
\hline 11:00 PM & 78 & 63 & 46 \\
\hline
\end{tabular}

To interpret these results, it is useful to note that India's 24-hour standard for rural exposure to $\mathrm{PM}_{10}$ is $100 \mathrm{ug} / \mathrm{m}^{3}{ }^{6}$ Over the daily cycle, outdoor pollution only rises to this level during one hour in the early evening (around 7:00 p.m.). However, the standard is exceeded in the indoor cooking area for 15 hours per day, and in living areas for 14 hours. During peak cooking periods, the $\mathrm{PM}_{10}$ concentrations rise to $845 \mathrm{ug} / \mathrm{m}^{3}$ in the cooking area and $683 \mathrm{ug} / \mathrm{m}^{3}$ in the living areas.

\footnotetext{
${ }^{6}$ Bangladesh does not seem to have an equivalent standard, but similar conditions in the two countries make the Indian standard relevant in this context.
} 


\section{Daily Exposure for Different Household Members}

We combine the information in Tables 2 and 3 to produce estimates of daily average $\mathrm{PM}_{10}$ exposure by age-sex group. To incorporate our hourly estimates for $\mathrm{PM}_{10}$ concentrations in cooking, living and outside areas, we adopt a set of conventions for assigning family members to locations during the 24-hour cycle. We provide a complete accounting of assignments for all age-sex groups in Appendix 1. We assume that infants and children 0-5 spend their single hour in the cooking area during the morning peak cooking time. We assume that women spend their cooking-area time during peak cooking periods, and that young children have their outside time during the mid-afternoon.

For older children, part of outside time reflects schooling schedules; we assume that the balance is devoted to play in the mid-late afternoon. Men's outside work times lie in the interval 7:00 AM 6:00 PM, with total hours reflecting the totals in Table 2. After accounting for cooking-area and outside times, all family members are assigned to inside living areas for periods that match the totals in Table 2. We compute daily exposure for members of each age-sex group by adding the 24 hourly $\mathrm{PM}_{10}$ concentrations for their assigned locations and calculating the mean concentration. Table 4 presents the results.

To check the general validity of our estimates for a typical household, we replicate our approach 236 times, using the mean $\mathrm{PM}_{10}$ concentration for each household monitored by our study. These concentrations vary widely, for reasons explored in our previous paper (Dasgupta, et al., 2004). We average the results and present them alongside the typical household results in Table 4. 
Table 4: Daily Average $\mathbf{P M}_{10}$ Exposure by Age and Gender*

\begin{tabular}{|l|c|c|c|c|}
\hline & \multicolumn{2}{|c|}{ Typical Household } & \multicolumn{2}{c|}{$\begin{array}{c}\text { 236 Monitored } \\
\text { Households }\end{array}$} \\
\hline Age & Female & Male & Female & Male \\
\hline $0-1$ & 216 & 214 & 209 & 195 \\
\hline $1-5$ & 212 & 212 & 199 & 192 \\
\hline $6-8$ & 173 & 172 & 156 & 163 \\
\hline $9-19$ & 207 & 174 & 196 & 194 \\
\hline $20-60$ & 227 & 116 & 221 & 118 \\
\hline $60+$ & 220 & 161 & 264 & 188 \\
\hline
\end{tabular}

* Outdoor $\mathrm{PM}_{10}=50$

** $\mathrm{PM}_{10}$ concentrations: cooking area 260; living area 210

*** Averages for 236 separate calculations using monitored $\mathrm{PM}_{10}$ levels

Differences in the two sets of results stem from variations in average pollution levels, household age-sex compositions, and time allocations by household members in the full set of monitored households. We present the results for the typical household in order to display exposure variations when inside/outside pollution concentrations and individuals' time allocations are held constant. In any case, the two sets of results are quite similar. The most striking finding is the high exposure -around 200 -- for infants and children, regardless of gender. Exposures for student-age individuals (619) are somewhat lower (although still quite high), and also similar for both sexes. The real genderbased divergence occurs among adults, with women's exposures nearly twice those for men in the age group 20-60, and about 40\% higher for older women (over 60).

Table 4 indicates that only adult males aged 20-60 have daily $\mathrm{PM}_{10}$ exposures low enough to approach the Indian standard $\left(100 \mathrm{ug} / \mathrm{m}^{3}\right)$. All other household members have significantly higher exposure levels, and the youngest children of both sexes have exposures that are among the most dangerous. Mortality from respiratory disease among children in this age range attests to the potent impact of such pollution levels.

Two features of our results warrant particular scrutiny. First, although attention has traditionally focused on pollution in cooking areas, our results suggest that simultaneous pollution in living areas is 
the true culprit. This is particularly true for young children, who spend only one hour per day in cooking areas, on average. Living-area pollution is only moderately below cooking-area pollution and follows the same cycle, so most daily inhalation of particulates occurs in the living areas. Adult males have lower exposures simply because they are out of the house for many more hours per day.

Second, we should qualify our results with a cautionary note about the impact of very intense pollution on women and children during peak cooking periods. It is possible that peak pollution during a few hours per day causes disproportionate health damage. Currently-available scientific evidence suggests that health damage is associated with daily average exposure levels, not peak hourly exposures. However, the evidence is far from conclusive, and it is mostly derived from research on outdoor pollution effects in industrial economies. ${ }^{7}$ Given the intensity of hourly pollution "spikes" during cooking in many Bangladeshi households, further research on this issue seems justified.

\section{Reducing Exposure for Young Children}

We use the case of infants (age 0-1) in our typical household to illustrate some implications of our results. We focus on infants because their documented vulnerability to indoor pollution seems to be the greatest. Our example applies to both male and female infants, since Table 4 shows that gender only makes a slight difference for daily exposure ( $216 \mathrm{ug} / \mathrm{m}^{3}$ for females vs. 214 for males).

Figure 4 presents a simple experiment with data for the typical household. Starting with the status quo, with infants spending 3 hours outside in mid-afternoon, we optimize the 3 -hour outside period by switching to other times (e.g., 8:00 AM) that provide the greatest relief from indoor

7 Studies of short exposures to outdoor particulate concentrations suggest some impact on heart rate variability and the rate of heart attacks. However, a recent study in Palm Springs, California suggests that the short-period effect disappears when 24-hour average exposure is controlled for. Similarly, average exposures seem to dominate day-to-day variations in daily time series studies. Our thanks to Dr. Bart Ostro, Chief, California Office of Environmental Health Hazard Assessment, for his insights. 
pollution. Then we add 3 more hours outside, sequentially choosing times that yield the greatest incremental reductions in daily $\mathrm{PM}_{10}$ exposure. We plot the results in Figure 4.

Figure 4: Optimum Outside Hours and Daily $\mathbf{P M}_{10}$ Exposure for Infants

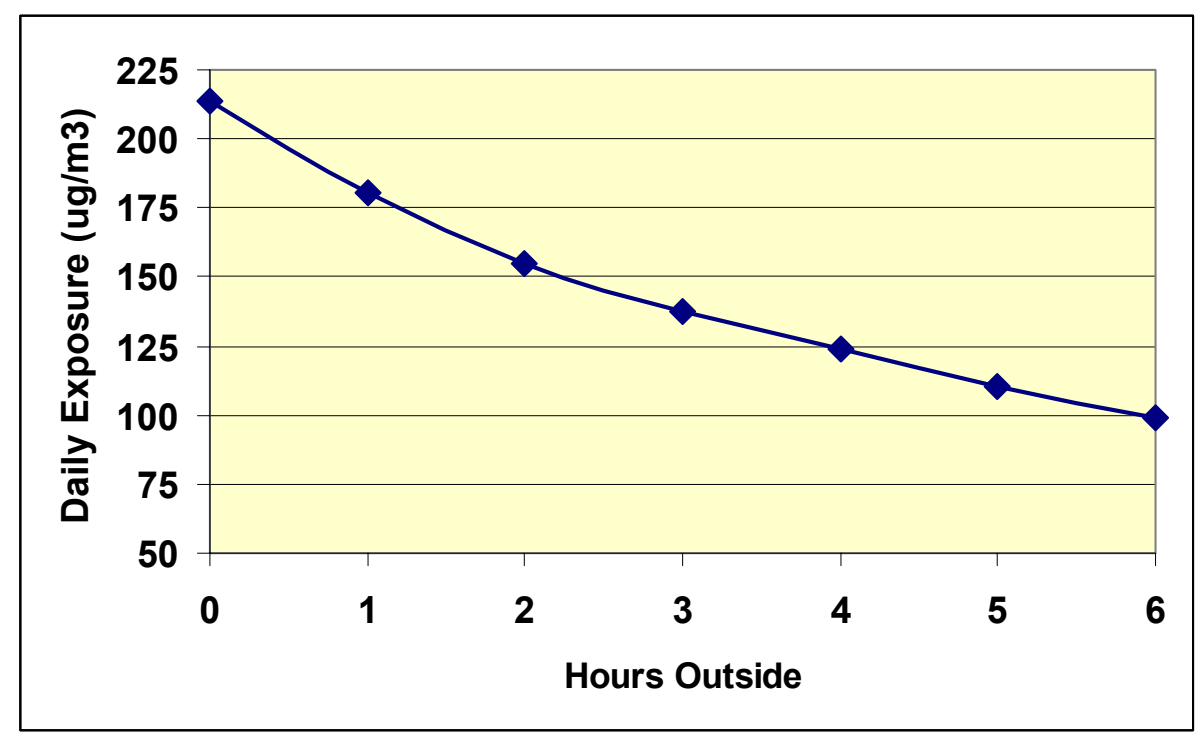

Figure 4 indicates that keeping infants outside during an optimally-chosen 6-hour period during peak cooking times (7:00 - 10:00 AM; 5:00 - 7:00 PM) would reduce daily $\mathrm{PM}_{10}$ exposure to the Indian standard level $\left(100 \mathrm{ug} / \mathrm{m}^{3}\right)$. Since approximately half of the sample households have $\mathrm{PM}_{10}$ concentrations above the mean level for our survey population $\left(260 \mathrm{ug} / \mathrm{m}^{3}\right.$ in cooking areas, $210 \mathrm{in}$ living areas), the potential reduction in exposure for infants in many homes could be much greater. ${ }^{8}$

Our results suggest that for households whose young children are kept inside during peak cooking periods, simply moving the children outside when weather permits could yield significant health improvements. Household members assigned to outside supervision would also benefit from reduced pollution. In cases where family help is scarce, it might be possible for several households to pool supervision during peak periods. While this might create some inconvenience, families might

8 We recognize that our illustration achieves such large reductions by assuming that infants are outside during the least desirable time in the status quo situation (i.e., the mid-afternoon period when indoor pollution is also relatively low). However, we believe that our essential point is generally valid - optimally-chosen outside time for infants has the potential for considerable reduction of health damage. 
well consider this option if they recognized the potential health benefits for their children. By the same logic, of course, other family members would benefit from extending their outside time during peak cooking periods.

\section{Comparison with Results for India}

A recent study of IAP exposure in India (World Bank, 2002) provides a useful point of comparison for our results. The India study also considers different age-sex groups, cooking vs. living areas, and cooking vs. non-cooking times. Its conclusions are similar to our findings in some respects:

Whereas women, in their traditional capacity as cooks, suffer from much greater average daily exposures than other family members, adult men experience the least exposure. Among noncooks, those who are most vulnerable to the health risks of IAP - young children and elderly people - tend to experience higher levels of exposure because they spend more time indoors.

(World Bank (2002), p. 3)

As Table 4 shows, we also find large differences between women and men in exposure to air pollution. ${ }^{9}$ However, we find essentially no difference in exposure for women and young children of both sexes. We also find relatively small differences between women's exposures and exposures for adolescents of either sex. The essential difference between our results and the India results lies in our findings for pollution in living areas. We find average living-area pollution concentrations to be much closer to cooking-area concentrations, and our 24-hour monitoring data indicate that daily pollution cycles are close to identical for the two areas. As a result, time spent in living areas does not provide much relief from pollution exposure. Time spent outside the house therefore emerges as the key variable in our analysis, and adult males have much smaller pollution exposure simply because of their outside orientation.

\footnotetext{
9 As we note in our previous paper (Dasgupta, et al., 2004), average $\mathrm{PM}_{10}$ concentrations are smaller in our study.
} 


\section{Income, Education and Exposure}

Households' $\mathrm{PM}_{10}$ concentrations and individuals' location patterns combine to produce pollution exposures for family members. As we have shown in Dasgupta, et al. (2004), household pollution levels are highly sensitive to fuel choices, cooking locations and construction materials that affect ventilation. Each of these factors may, in turn, be affected by household income and adult education levels. If such effects are significant, they may be partly related to pollution-related problems, and partly to other factors (e.g., status issues related to choice of building materials and cooking locations). The positive income elasticity of clean fuel choice should also have a significant effect, at least in urban areas where clean fuel is a feasible option. Education may affect adults' awareness of the relationship between pollution exposures and health risks for infants and young children. If this is the case, then we might expect children to spend more time outside in more highlyeducated families. We are agnostic about whether income could also have an effect in this context.

We test the effects of income and education on pollution exposure factors, using our full sample of households in seven regions of Bangladesh. We use the econometric results in our previous paper to estimate $\mathrm{PM}_{10}$ in each household, incorporating the combined effects of fuel choices and structural characteristics (cooking locations and construction materials). We regress estimated $\mathrm{PM}_{10}$ on household income (in \$US per day) and the average education levels of men and women in the household. For infants and young children, we regress time spent outside on the same variables. We present the regression results for both exposure components in Table 5. 
Table 5: Education, Income and Pollution Exposure for Children

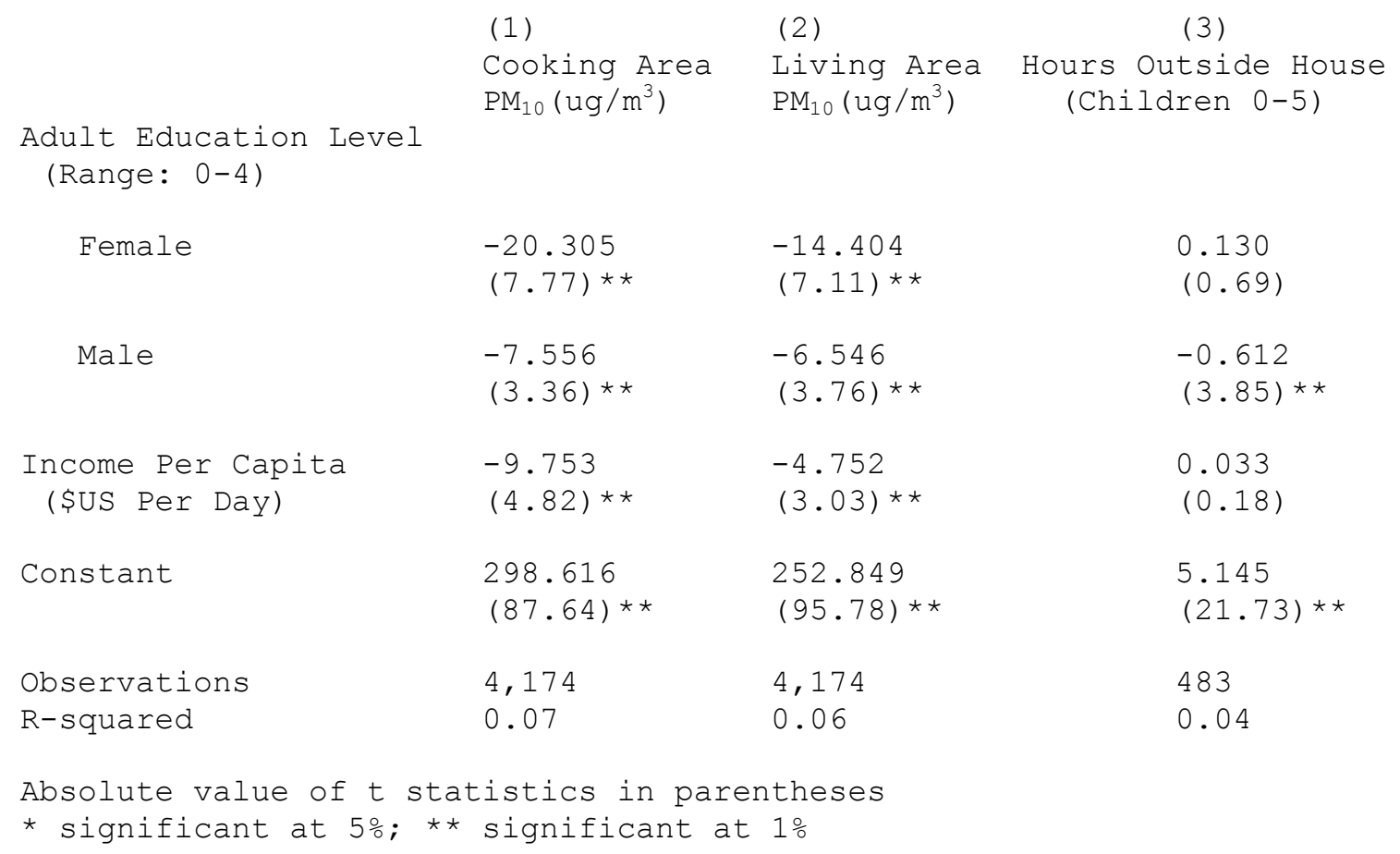

Education and household per capita income have the expected effects on determinants of indoor air pollution. All estimated effects are large, highly significant, and have the expected negative sign. Women's education has a particularly large effect. Our results indicate that when men's and women's education levels jointly increase from 0 (no primary schooling) to 4 (post-secondary education), predicted $\mathrm{PM}_{10}$ in the cooking area decreases by about $110 \mathrm{ug} / \mathrm{m}^{3}$. This is a very large effect, since the average $\mathrm{PM}_{10}$ concentration for our 236 monitored households is $260 \mathrm{ug} / \mathrm{m}^{3}$. Each increase of \$US $1.00 /$ day is associated with a decline of $10 \mathrm{ug} / \mathrm{m}^{3}$, so the predicted reduction over the sample income range (less than $\$ .50 /$ day to $\$ 15.00 /$ day) is approximately $150 \mathrm{ug} / \mathrm{m}^{3}$.

Although education and income strongly reduce average pollution, they do not seem to change children's daily activity patterns in ways that reduce pollution exposure. Children's hours spent outdoors are not significantly affected by women's education or income per capita, and the measured 
effect of adult male education is actually perverse (children of more educated men spend less time outdoors).

We tentatively conclude that parents' education and income do affect children's pollution exposure, but only through the determinants of pollution. We extend the analysis by estimating separate regressions for fuel choice and structural determinants of pollution (cooking locations, construction materials). We combine information on fuel choices and structural characteristics into two separate indices, with weights determined by the regression coefficients for cooking-area pollution determinants in Table 7 of Dasgupta, et al. (2004). Table 6 presents the results, which suggest that female education, male education and family income all have large, highly-significant effects on pollution via fuel choice. Female education has an equivalent effect on the structural determinants, but male education and family income do not appear to be significant. As in the composite result (Table 5), female education appears to be the strongest and most pervasive determinant of arrangements that reduce indoor air pollution.

Table 6: Income, Education and Determinants of Indoor Air Pollution

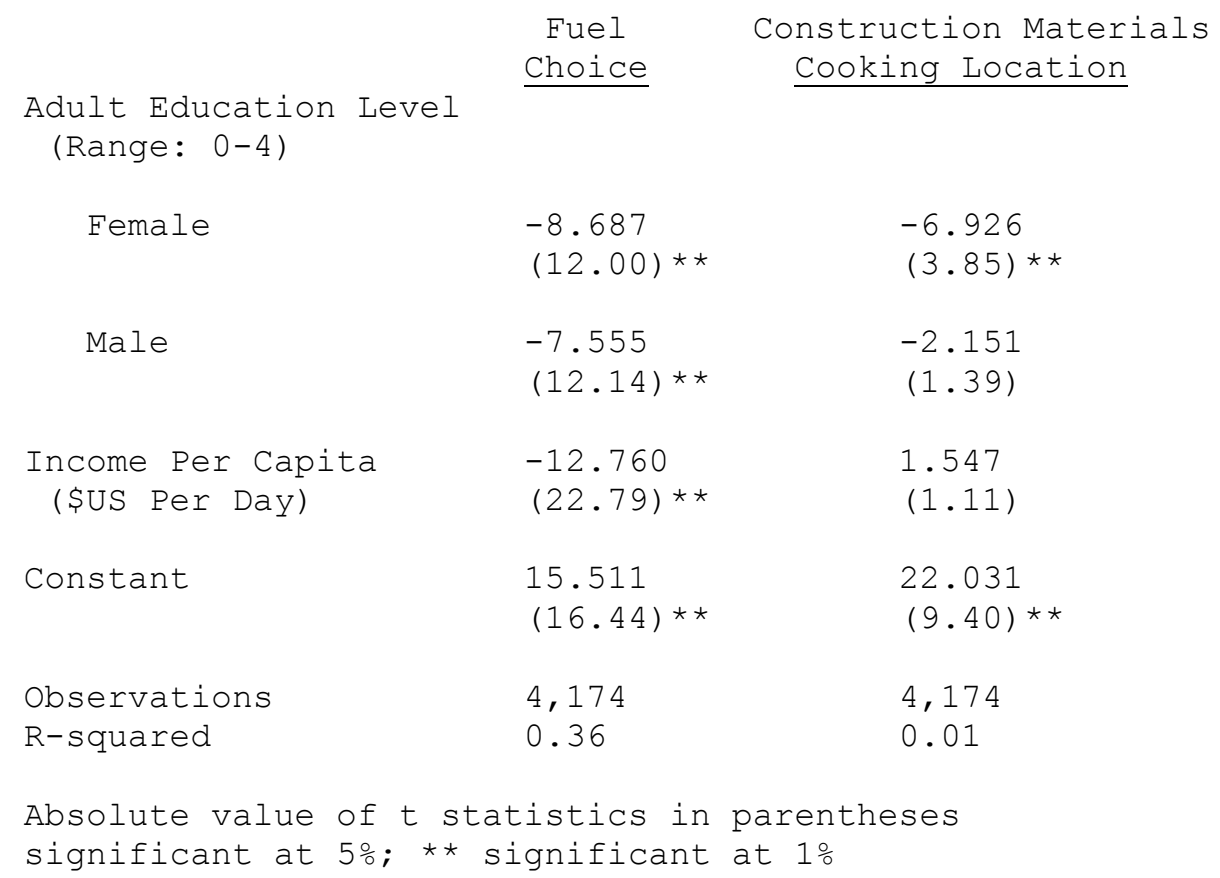


We illustrate our overall results in Table 7, which presents predicted average $\mathrm{PM}_{10}$ levels in cooking and living areas by income and women's education.

Table 7: Average Predicted $\mathrm{PM}_{10}$ Concentrations $\left(\mathrm{ug} / \mathrm{m}^{3}\right)$ By Income and Women's Education Level

\begin{tabular}{|c|c|c|c|c|c|c|c|c|c|c|}
\hline & \multicolumn{10}{|c|}{ Women's Education Level (Range: $0-4$} \\
\hline & \multicolumn{5}{|c|}{ Cooking Area } & \multicolumn{5}{|c|}{ Living Areas } \\
\hline $\begin{array}{l}\text { Income Per Capita } \\
\text { (\$US / Day) }\end{array}$ & $\begin{array}{c}0- \\
1.00\end{array}$ & $\begin{array}{l}1.01- \\
2.00\end{array}$ & $\begin{array}{l}2.01- \\
3.00\end{array}$ & $\begin{array}{c}3.01 \\
+\end{array}$ & Total & $\begin{array}{c}0- \\
1.00\end{array}$ & $\begin{array}{l}1.01- \\
2.00\end{array}$ & $\begin{array}{l}2.01- \\
3.00\end{array}$ & $\begin{array}{c}3.01 \\
+\end{array}$ & Total \\
\hline $0-\$ .50$ & 267 & 305 & 205 & 261 & 272 & 229 & 257 & 183 & 234 & 233 \\
\hline$\$ .51-\$ 1.00$ & 314 & 222 & 220 & 206 & 260 & 269 & 193 & 196 & 185 & 225 \\
\hline$\$ 1.01-\$ 2.00$ & 267 & 205 & 168 & 162 & 211 & 230 & 187 & 163 & 158 & 191 \\
\hline$\$ 2.01-\$ 5.00$ & 266 & 212 & 151 & 148 & 188 & 236 & 198 & 152 & 148 & 179 \\
\hline$\$ 5.01+$ & 373 & 135 & 150 & 135 & 163 & 308 & 147 & 157 & 147 & 166 \\
\hline Total & 278 & 246 & 192 & 181 & 254 & 239 & 213 & 178 & 173 & 221 \\
\hline
\end{tabular}

Table 7 is generally consistent with our econometric results, while suggesting that some non-

linear effects are not captured by the linear regression model in Table 5. For example, education seems to have minimal effects on pollution for the lowest income group, but pronounced effects when income is higher. Similarly, increased income doesn't reduce pollution consistently for the lowest education group, but it has a strong effect at higher levels of education. The combined effects of income and women's education are sufficient to approximately halve $\mathrm{PM}_{10}$ pollution, from near 300 $\mathrm{ug} / \mathrm{m}^{3}$ in the poorest, least educated groups to around 150 in the highest-income, best-educated groups. As our sample composition statistics clearly show in Table 8, most of the individuals (and households) in our survey are in the four table cells associated with the lowest income and education levels.

Table 8: Sample Composition

\begin{tabular}{|c|c|c|c|c|c|}
\hline & \multicolumn{4}{|c|}{ Adult Female Education Level } & \\
\hline $\begin{array}{l}\text { Income Per Capita } \\
\text { (\$US / Day) }\end{array}$ & $0-1.00$ & $1.01-2.00$ & $2.01-3.00$ & $3.01+$ & Total \\
\hline $0-\$ .50$ & 1,703 & 455 & 81 & 52 & 2,291 \\
\hline$\$ .51-\$ 1.00$ & 585 & 553 & 172 & 78 & 1,388 \\
\hline$\$ 1.01-\$ 2.00$ & 184 & 251 & 121 & 76 & 632 \\
\hline$\$ 2.01-\$ 5.00$ & 32 & 59 & 41 & 61 & 193 \\
\hline$\$ 5.01+$ & 11 & 18 & 25 & 54 & 108 \\
\hline Total & 2,515 & 1,336 & 440 & 321 & 4,612 \\
\hline
\end{tabular}




\section{Summary and Conclusions}

In this paper, we have investigated individuals' exposure to indoor air pollution (IAP) in Bangladesh. We have analyzed exposure at two levels: differences within households attributable to family roles, and differences across households attributable to income and education. Within households, we have related individuals' exposure to pollution in different locations during their daily round of activity. We find high levels of exposure for children and adolescents of both sexes, with particularly serious exposure for children under 5. Among prime-age adults, we find that men have half the exposure of women (whose exposure is similar to that of children and adolescents). We also find that elderly men have significantly lower exposure than elderly women.

Across households, we draw on results from our previous paper (Dasgupta, et al., 2004), which relates pollution variation across households to choices of cooking fuel, cooking locations, construction materials and ventilation practices. We find that these choices are significantly affected by family income and adult education levels (particularly for women). Overall, we find that the poorest, least-educated households have twice the pollution levels of relatively high-income households with highly-educated adults.

To summarize, we find that young children and poorly-educated women in poor households face pollution exposures that are four times those of men in higher-income households organized by more highly-educated women. In our previous paper, we recommended feasible changes in cooking locations, construction materials and ventilation practices that could greatly reduce average household pollution levels. In this paper, we consider measures for narrowing the exposure gap within households. We focus particularly on changes for infants and young children, since they suffer the worst mortality and morbidity from indoor air pollution, but our findings also apply to women and adolescents. Our recommendations for reducing their exposure are based on a few simple, robust 
findings: Hourly pollution levels in cooking and living areas are quite similar because cooking smoke diffuses rapidly and nearly-completely into living areas. At the same time, outdoor pollution is far lower. At present, young children are only outside for an average of 3 hours per day. For children in a typical household, pollution exposure can be halved by adopting two simple measures: increasing their outdoor time from 3 to 5 or 6 hours per day, and concentrating outdoor time during peak cooking periods. We recognize that weather and other factors may intervene occasionally, and that child supervision outdoors may be difficult for some households. However, the potential benefits are so great that neighbors might well agree to pool outdoor supervision once they became aware of the implications for their children's health. 


\section{References}

Bruce, N., 1999, Lowering Exposure of Children to Indoor Air Pollution to Prevent ARI: the Need for Information and Action, Capsule Report (3), Environmental Health Project, Arlington VA.

Dasgupta, S., M. Huq., M. Khaliquzzaman, K. Pandey, and D.Wheeler, 2004, "Indoor Air Quality for Poor Families: New Evidence from Bangladesh," World Bank, Development Research Group Working Paper No. 3393, August.

Galassi, C., B. Ostro, F. Forastiere, S. Cattani, M. Martuzzi and R. Bertollini, 2000, "Exposure to PM10 in the Eight Major Italian Cities and Quantification of the Health Effects," presented to ISEE 2000, Buffalo, New York, August 19-22.

Kirkwood, B., S. Gove, S. Rogers, J. Lob-Levyt, P. Arthur and H. Campbell, 1995, "Potential Interventions for the Prevention of Childhood Pneumonia in Developing Countries: A Systematic Review," Bulletin of the World Health Organization, 73: 793-798.

Murray, C. and A. Lopez (eds.), 1996, The Global Burden of Disease, Cambridge MA: Harvard School of Public Health, WHO, World Bank.

Smith, K., 2000, "National Burden of Disease in India From Indoor Air Pollution," Proceedings of the National Academy of Science USA, (97) 13286-13293.

Smith, K. and S. Metha, 2000, The Global Burden of Disease from Indoor Air Pollution in Developing Countries: Comparison of Estimates, Prepared for the WHO/USAID Global Technical Consultation on Health Impacts of Indoor Air Pollution in Developing Countries.

Smith, K., 1993, "Fuel Combustion, Air Pollution Exposure, and Health: the Situation in Developing Countries," Annual Review of Environment and Energy, 18:526-566.

Smith, K., Y, Liu, J. Rivera, et al., 1993. "Indoor air quality and child exposures in highland Guatemala," Proceedings of the 6th International Conference on Indoor Air Quality and Climate, University of Technology, Helsinki, 1:441-446.

Von Schrinding, Y., N. Bruce, K. Smith, G. Ballars-Treemeer, M. Errati, and K. Lvovsky, 2001, Addressing the Impact of Household Energy and Indoor Air Pollution on the Health of the PoorImplications for Policy Action and Intervention Measures, WHO Commission on Macroeconomics and Health Working Paper, WG5:12.

WHO, 2001, Informal Consultation on Epidemiologic Estimates for Child Health 11-12 June 2001, Department of Child and Adolescent Health Development, WHO, Geneva (http://www.who.int/child-adolescent-health/New Publications/Overview/).

World Bank, 2002, “India: Household Energy, Indoor Air Pollution, and Health,” ESMAP / South Asia Environment and Social Development Unit, November. 
World Bank, 2001, Making Sustainable Commitments: An Environment Strategy for the World Bank, July. 
Appendix I: Hourly Household Member Locations, by Age and Gender (X = Presence in a Location)

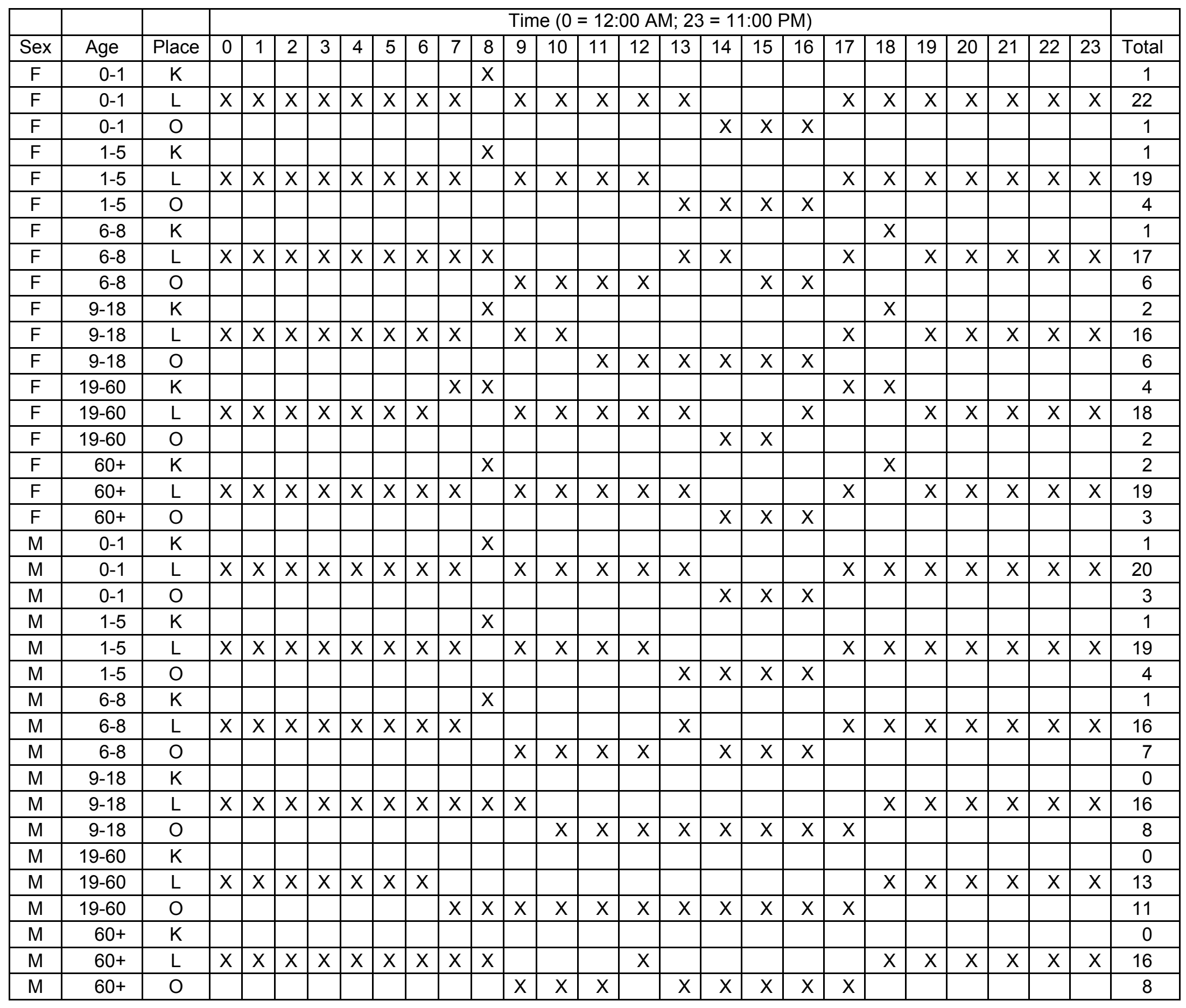

